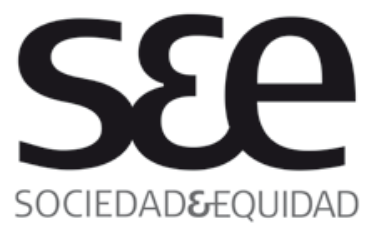

SOCIEDADEEQUIDAD

\section{Relaciones de género y participación social de mujeres peruanas inmigrantes en la Región Metropolitana de Chile}

Gender relations and social participation of Peruvian immigrant women in the Metropolitan Region of Chile

$\begin{array}{ll}\text { Nombre: } & \text { Clara Patricia Pantoja Bohórquez } \\ \text { Filiación: } & \text { UNIMINUTO - Corporación } \\ & \text { Universitaria Minuto de Dios } \\ \text { País: } & \text { Colombia } \\ \text { Correo: } & \text { cpantoja@uniminuto.edu }\end{array}$

\title{
Resumen
}

En el presente artículo se analizan los discursos de un grupo heterogéneo de mujeres peruanas que participan de manera activa en organizaciones sociales de inmigrantes que operan en la Región Metropolitana de Santiago. Desde un abordaje cualitativo se busca interpretar las significaciones que las mujeres otorgan a sus relaciones de género en el marco del proceso migratorio y la manera en que éstas relaciones se articulan con su participación; se enfatizan aquellos elementos que son problematizados por las mujeres, dando cuenta de los posibles cambios y transformaciones en las relaciones de género dominantes, pero también los aspectos que son naturalizados. Dentro de las conclusiones se señalan los elementos que restringen la vinculación y el mantenimiento en los espacios participativos, relacionados con la inserción de las mujeres migrantes peruanas en un ámbito laboral caracterizado por una estratificación social basada en nacionalidad, género y clase; también emergen como aspectos importantes, las relaciones de dominación en la pareja, la naturalización de la maternidad y la identidad femenina en función de otros. Las mujeres también dan cuenta de las prácticas de movilización, agencia y resistencia que cuestionan y tensionan las relaciones de poder desiguales en las cuales se encuentran insertas. Se resalta en el discurso, la construcción de un sujeto múltiple que cuestiona la categoría "mujer inmigrante" como homogénea y estática.

\section{Palabras Claves}

Migración, Género, Participación, Análisis de discurso

1 La autora es Psicóloga, Magister en Psicología Mención en Psicología Comunitaria. Sus líneas de investigación son: Género y Derechos Humanos; Conflicto armado; Memoria Histórica. 


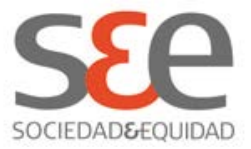

\begin{abstract}
In this paper we analyze the discourses of a heterogeneous group of Peruvian women who are actively involved in immigrant social organizations operating in the Metropolitan Region of Santiago. From a qualitative approach we seek to interpret the meanings that women give to their gender relations in the context of the migration process and how these relationships are articulated with their social participation. The analysis emphasizes those elements that are problematized or stressed by women, accounting for possible changes and transformations of dominant gender relations, but also those aspects that are naturalized and limit their participation. The conclusions of the study outline some elements that restrict their linkage and maintenance in participatory spaces. These elements are employment characterized by social stratification based on nationality, gender and class; another outstanding factor are relationships of domination partnerships, naturalization of motherhood and female identity in the service of others. Women also report agency and resistance practices that question unequal power relations in which they are embedded. In addition to these elements, their discourses question de category of "immigrant woman" in terms of its homogeneity and fixation, constructing it as a multiple and shifting subject.
\end{abstract}

\title{
Keywords
}

Migration, Gender, Participation, Discourse analysis.

$* * *$

\section{Introducción}

La incorporación del enfoque de género en los diferentes estudios sobre migración, pone en evidencia la creciente feminización de los movimientos migratorios tanto en el contexto global (Pedone, 2006; Lipszyc, 2004), como en el ámbito regional de Latinoamérica y particularmente en las migraciones peruanas a Chile (Stefoni, 2001; 2004; Zabala y Rojas, 2005; Tijoux, 2007).

Esta visibilización de la movilidad femenina, como primer eslabón en la cadena migratoria, puede dar cabida a múltiples cuestionamientos en torno a la transformación de las relaciones de género; por ejemplo nos lleva a preguntarnos si la entrada de las mujeres a un contexto que maneja unas relaciones sociales y culturales diferentes, así como las posibilidades de distanciarse de los sistemas de control social de su país de origen, les abre un nuevo campo de posibilidad que les permita re-significar sus relaciones de género y aportar a la construcción de nuevas miradas sobre el ser mujer. 


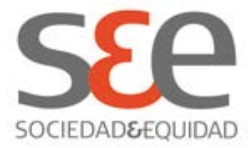

Distintas investigaciones han planteado que muchas mujeres inmigrantes se encuentran coartadas en el ejercicio de sus derechos en el país de destino, en el cual son sujetos de discriminación y exclusión (informe UNFPA, 2006; Pedone, 2006 y Lipzyc, 2004), puesto que la inserción laboral en el contexto de destino por lo general, implica un múltiple proceso de discriminación en cuanto a ser inmigrante, ser mujer, ser de otra clase social y otra etnia. Particularmente en Chile, un alto porcentaje de las actividades laborales de las inmigrantes están inscritas en la cadena de cuidados que las mujeres del país receptor han dejado de asumir por insertarse en labores productivas más valoradas social y económicamente, produciendo la transferencia transnacional de las desigualdades de género (Stefoni, 2001; 2004 y Zabala y Rojas, 2005).

Así, las cargas culturales y sociales del país de origen, y los procesos de exclusión en los países de destino, podrían indicar que las mujeres se encuentran limitadas en su posibilidad de re-significar dichas relaciones de género $y$, por el contrario, el proceso migratorio les carga de una serie de funciones productivas además de las reproductivas, pues muchas se convierten en sostén económico de las familias de origen.

Asumiendo este panorama, nos interesó indagar entonces ¿qué está ocurriendo al interior de las relaciones de género para el caso de las mujeres inmigrantes peruanas en Chile? ¿Cuáles son aquellas normativas socio-culturales del país de origen y del país de destino que constriñen su accionar? ¿En qué aspectos radica su posibilidad de agencia para asumir nuevas prácticas sociales, nuevas redes y vínculos en el país de origen?

Siguiendo esta misma argumentación se genera la reflexión desde la perspectiva de las mujeres que participan en organizaciones de inmigrantes que actualmente funcionan en Santiago, ya que, por una parte, estos colectivos operan al interior de las regulaciones determinadas por los aspectos macrosociales (económicos, políticos y culturales) -y por tanto encuentran limitación en ellos- pero, a la vez, actúan como redes comunitarias de defensa de derechos que generan resistencia y agencia desde las mujeres frente a los diferentes condicionantes estructurales. En estas redes circula información y apoyo social que desde una mirada micro y meso-social puede dar cuenta de transformaciones en las relaciones de género en estos espacios. Así entonces, la participación de las mujeres en tanto acción social, empoderamiento, reivindicación de derechos o apoyo social a otros inmigrantes, se constituye en agente que puede generar nuevas prácticas y significaciones en torno a las relaciones de género en el contexto actual y, así mismo, se convierte en una oportunidad política de movilización y de construcción de nuevas prácticas. 


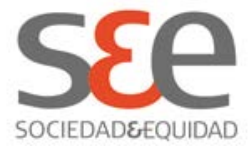

\section{Aclaraciones metodológicas}

La investigación se enmarcó dentro de un enfoque cualitativo, buscando aprehender el proceso de interpretación de los sujetos de estudio y la comprensión de los procesos y de la realidad social, más que su predicción (Iñiguez, 2008). Siguiendo un diseño de investigación flexible y desde una perspectiva holística, las personas, escenarios y grupos no fueron abordados como variables, sino considerados como un todo, buscando comprenderlas dentro del marco de referencia de ellas mismas (Taylor y Bogdan, 1986).

Se desarrolla una investigación de tipo Interpretativo, fundamentada en el planteamiento de que "el propio modo de participación del ser humano en el mundo, pasa irremediablemente por la comprensión (Gadamer, 1960 citado por Ibáñez, 1990). Partimos de la consideración de que todo saber formulable, descansa sobre presupuestos hermenéuticos y sobre las pre-interpretaciones inherentes al lenguaje (Ibáñez, 1990). El marco de interpretación que se otorga a los datos producidos, es relativo a nuestra posición dentro de una tradición histórica y cultural, así como a los anclajes culturales y lingüísticos del sistema de significados que articulan dicha interpretación (Ibáñez, 1990).

Se optó por el método discursivo, asumiendo el discurso como práctica social constitutiva de los procesos sociales; por lo tanto se consideraron tres dimensiones centrales: 1) el discurso como texto - resultado oral o escrito de la producción discursiva- 2) Como práctica discursiva enmarcada en una situación social concreta y 3) como ejemplo de práctica social, que no solo expresa 0 refleja identidades, prácticas, relaciones, sino que las construye y las conforma; paralelamente, se trata de revelar cuáles son las implicaciones sociales de este proceso de construcción (Iñiguez, 2003). Con base en lo anterior, la aproximación desde esta perspectiva centra su estudio en aquellas acciones sociales que se ponen en práctica a través del discurso; para esta investigación, las relacionadas con la significación de las relaciones de género en el contexto de la participación de las mujeres en las organizaciones sociales.

Como técnicas para la producción de datos se utilizaron entrevistas abiertas a profundidad, ya que buscamos aproximarnos a las experiencias de los sujetos. A partir de algunos temas guías, se realizaron doce (12) entrevistas orientadas a producir la información en torno a aspectos claves a través de los cuales se desarrollaba cada encuentro.

El procedimiento de análisis de datos se hizo a través de un análisis de discurso, siguiendo tres momentos fundamentales: 1) lectura global y segmentación del corpus para identificar la estructura argumentativa general, y establecer los ejes temáticos presentes en el corpus; 2) un análisis de enunciación en el cual se analizaron las diferentes deixis de sujeto, tiempo y 


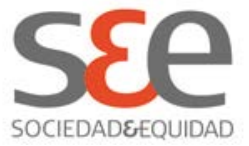

lugar desde los cuales se ancla el discurso de las entrevistadas, que dan cuenta de posicionamientos diversos al interior del discurso; 3) un análisis pragmático, tomando en cuenta el uso que se hace del lenguaje, y analizando al interior del corpus, las relaciones que el discurso promueve, mantiene o produce; se analizaron los elementos que aparecen problematizados, naturalizados, polarizados o tensionados en el discurso, y que se presentan de manera concisa más adelante.

Colectivo de referencia y muestra

El colectivo de referencia estuvo constituido por mujeres mayores de edad, participantes de organizaciones sociales y culturales de inmigrantes que operaban en la Región Metropolitana de Santiago de Chile (RM) durante el año 2010. Se realizó un mapeo de las organizaciones de inmigrantes existentes en la $\mathrm{RM}$, encontrando que el mayor grado organizativo está dado en los colectivos peruanos, y son éstos los que han ganado mayor visibilidad y reconocimiento.

Para la selección de la muestra se estableció contacto con la mayoría de éstas organizaciones, sin embargo no todas tienen un funcionamiento continuo y otras no se mostraron interesadas en participar; finalmente se focalizó la investigación en dos organizaciones de carácter social y una de índole cultural, que mostraron apertura y disposición hacia la investigación. Estas organizaciones son colectivos liderados por hombres y mujeres de origen peruano, que trabajaban con inmigrantes de diferentes países latinoamericanos (particularmente Bolivia, Perú y Colombia); una de las organizaciones sociales trabajaba específicamente con mujeres, la otra estaba enfocada particularmente al trabajo con infancia y a la visibilización de derechos; la organización cultural contactada, trabajaba con hombres y mujeres adultos a través del rescate y difusión de la danza peruana. Los nombres de las organizaciones fueron omitidos para proteger su identidad y resguardar la confidencialidad de la investigación.

Al interior de dichas organizaciones se establece el contacto directo con las mujeres mediante la activación de la bola de nieve; esto implica que desde la perspectiva de investigación cualitativa no se pretende que la muestra sea representativa del colectivo de mujeres peruanas inmigrantes en Chile, pero sí que recoja diferentes posiciones de sujeto que permitan una mayor amplitud de significaciones en torno al género y la participación social. Se selecciona así una muestra de doce (12) mujeres, entre veintiocho (28) y cincuenta (50) años, a partir de un muestreo estratégico o intencional, atendiendo a los siguientes criterios: 


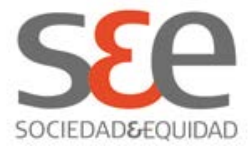

a) Permanencia: Interesó producir información sobre mujeres que hubieran sido socializadas en Perú, fueran residentes en Chile desde hace un año como mínimo y que hubieran permanecido al menos un año vinculadas a la organización de manera continua y frecuente; el grupo de mujeres entrevistadas han sido todas socializadas en Perú, residen en Chile en un promedio de 12 años y llevan entre 3 y 10 años de participación al interior de una sola organización, o de diversas organizaciones.

B) Diversificación: buscando favorecer la amplitud en las significaciones alrededor del género y realizar un análisis desde diversas posiciones de sujeto, se tomaron como criterios de diversificación la edad, el estado civil, la maternidad, el nivel de estudio y la inserción en el ámbito laboral. Por tanto, las mujeres seleccionadas se ubican entre los 28 y 50 años de edad, con o sin hijos, heterosexuales, algunas casadas, otras solteras y divorciadas; se entrevistaron mujeres profesionales, otras con educación secundaria y la mayoría con formación técnica no convalidada en Chile; todas insertas en el ámbito laboral, en diversos rubros que iban desde el trabajo en el servicio doméstico (puertas adentro y puertas afuera), otras dedicadas al trabajo informal en ventas, el trabajo social a través de la organización, entre otros. Todas ellas, profesionales y técnicas han trabajado en rubros no relacionados con su profesión, y de menor cualificación.

\section{Aclaraciones teóricas}

Nos interesa tomar las relaciones de género desde la perspectiva de Gregorio (2004), quien las concibe como sistemas complejos de relaciones, en los que la desigualdad debe entenderse a partir de la relación entre las elaboraciones culturales, los significados de los hechos sociales y las relaciones políticas y económicas dentro de contextos específicos en los que éstas se reproducen, pero también cambian en función de las y los actores implicados. En este sentido, interesa develar cómo la diferencia de género y otras asociadas a ésta -extranjería, raza, cultura- se construyen socialmente para producir desigualdad y justificar formas de violencia o dominación, y cómo se estructura en contextos específicos a partir de representaciones culturales de lo femenino y lo masculino y de prácticas sociales de jerarquización.

Así, partimos de reconocer la existencia de una relación de poder desigual entre hombres y mujeres que se encuentra arraigada en nuestra cultura occidental, y que ha legitimado una serie de binarismos jerárquicos (privado/público, natural/cultural, dominación/sumisión, producción/ reproducción) que operan a través de prácticas y discursos que han llevado a que la mujer ocupe un lugar de desventaja frente al hombre, y han establecido una serie de normativas sobre lo adecuado e inadecuado para uno y otro, en las que variables como la etnia, la clase, la generación, entre otras, 


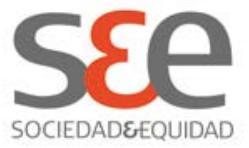

operan como limitantes o facilitadores al interior de dichas relaciones de dominación/ sumisión.

Para el análisis de datos se retoman los planteamientos de Bourdieu (2000) sobre la "Dominación Masculina" resaltando de su teoría los siguientes aspectos fundamentales:

a) La manifestación de la visión dominante masculina, a partir de prácticas, discursos, objetos, espacios, que es naturalizada y legitimada en tanto se presenta en "el estado objetivado" así como "en el estado incorporado".

b) las relaciones de dominio se inscriben bajo principios de división, que conducen a clasificar todas las prácticas y las cosas a partir de la oposición entre lo masculino y lo femenino, prácticas que a la vez, legitiman la visión dominante como natural.

c) La violencia simbólica impone una coerción, que se instituye por medio del reconocimiento extorsionado que el dominado no puede dejar de prestar al dominante al no disponer, para pensarlo y pensarse, más que de instrumentos de conocimiento que tiene en común con él y que no son otra cosa que la forma incorporada de la relación de dominio; así, los dominados construyen las relaciones de poder desde el mismo punto de vista de los que afirman su dominio.

d) Al ser fruto de la inscripción en el cuerpo de una relación de dominio, los dominados contribuyen a su propio dominio al aceptar tácitamente los límites que le son impuestos, o incluso al producir o reproducir mediante su práctica los límites abolidos en el ámbito del derecho.

Nos interesó tomar también a las relaciones de género como relaciones de poder; de acuerdo con Amigot y Pujal (2009) el género como dispositivo de poder realiza dos operaciones fundamentales e interrelacionadas: 1) la producción de la propia dicotomía del sexo y de las subjetividades vinculadas a ella y, 2) la producción y regulación de las relaciones de poder entre varones y mujeres; el dispositivo de género opera subordinando a las mujeres; no obstante, el género siempre aparece en interacción con otros dispositivos de la desigualdad y en esa interacción se configuran experiencias específicas; esto último permite no olvidar la heterogeneidad que se da entre las mujeres y sus situaciones.

Por último, interesa rescatar también la capacidad de agencia y de resistencia a dichas relaciones de poder desiguales, y a situaciones de 


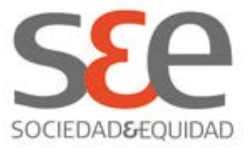

dominación, tomando al género como una práctica reiterativa en función de ciertas normas sociales, que a partir de su repetición (discursiva y performativa) las legitima, pero también a partir de las cuales es posible producir fisuras, quiebres y, por tanto, cambios en las relaciones de poder. Así pues, para Butler (2007), el precepto de ser de un género concreto, se genera mediante rutas discursivas: ser una buena madre, ser objeto heterosexualmente deseable, ser un trabajador capacitado, en definitiva, significar a la vez una gran cantidad de garantías que satisfacen una variedad de exigencias distintas.

Esta autora concibe el género como una construcción que reiteradamente disimula su génesis; el acuerdo colectivo tácito de actuar, crear y garantizar géneros diferenciados y polares, nos obliga a creer en su necesidad y naturalidad. El género sería entonces, para Butler (2007), una identidad construida, una realización performativa pero también es una regla que nunca puede interiorizarse del todo, y las posibilidades de transformación de género radican precisamente en la performatividad, como práctica de agencia y resistencia, es decir, al pensar las normas del género como la propia reiteración y actuación de esas mismas normas, ellas están siempre sujetas a la re-significación y a la renegociación, abiertas a la transformación social.

En los aspectos teóricos referentes a la migración, se tomaron elementos desde la Teoría de la articulación; enfoque desde el cual las migraciones serían procesos complejos en los cuales la configuración de vínculos y redes de relaciones entre el origen y el destino juegan un rol fundamental (Zabala y Rojas, 2005).

En los movimientos migratorios, concebidos como un sistema, pueden identificarse elementos interactivos en el transcurso del proceso cuya comprensión debe realizarse desde una perspectiva global, interpretándolo como un conjunto indivisible. Los migrantes, dentro de la organización social, se convierten en una categoría diferenciada de población, tanto en origen como en destino, delimitada por el concepto de desplazamiento (Arellano, 2004). En torno a este criterio, se va conformando un entramado superior, diferente de la suma de los miembros componentes de grupo, que les conecta e identifica, cuya importancia radica en su capacidad real de intercambio y relación, creciendo hasta convertirse en una gran red intangible sobre la que se desarrollan la mayor parte de los procesos migratorios (Gurack, 1998 citado por Arellano, 2004). El análisis de la vertiente colectiva del proceso permite establecer un puente entre las macro variables socioeconómicas y demográficas y los propios migrantes, mediante la introducción de la identidad colectiva y de los procesos grupales sujetos a ella (Arellano, 2004). 


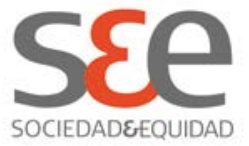

Desde la teoría de la articulación nos interesó retomar el concepto de red migratoria, definida como el conjunto de relaciones sociales que organizan y dirigen la circulación de trabajo, capital, bienes, servicios, información e ideologías entre las comunidades que envían migrantes y las que los reciben. Estas redes, en tanto instancias de autoayuda e intercambio, trasvase de información, etc. tenderían a reproducir las relaciones de género dominantes en la sociedad de origen. Sin embargo, el carácter de internacionalidad de la red y de interconexión entre dos sociedades, deja abierta la posibilidad de cambio en algunos aspectos en las relaciones entre los géneros (Zabala y Rojas, 2005).

A continuación se recogen las principales conclusiones construidas a partir del proceso de investigación, enfatizando en las significaciones que las mujeres peruanas otorgan a sus relaciones de género en el marco del proceso migratorio, y la manera en que estas significaciones se articulan con su vinculación y participación en colectivos de inmigrantes. Reiteramos que las prácticas sociales se toman no solo como reproducción del sistema sino también como contestación, y por lo tanto se sitúa el análisis en las posibilidades de cambio y acción social de las mujeres inmigrantes.

\section{Relaciones de género: cambios y continuidades a partir del proceso migratorio}

\section{Sujeto múltiple, múltiples identidades}

En primer lugar, es importante acotar que las mujeres participantes en esta investigación remarcan en sus discursos una crítica a "la mujer" y "la mujer peruana" como categoría homogénea y monolítica, poniendo de manifiesto que "No todas somos iguales", y que las construcciones en torno a su identidad, así como a las relaciones de género de las cuales dan cuenta, están marcadas por diferencias generacionales, regionales, urbano/rurales y de clases sociales.

“...no es lo mismo, yo no te podría decir, 'las mujeres del Perú todas son iguales', (...), yo no califico así ¿no? tampoco te puedo decir que las mujeres del norte son iguales a las del sur, o son iguales a, o las de lima son mejores, son peores" (Lina, inmigrante laboral, participante organización cultural)

Desde esta perspectiva, las mujeres entrevistadas destacan lo rural, las clases sociales más bajas y la generación de sus padres, como aquellas menos permeadas por los cambios y más abocados a la repetición y legitimación de los binarismos jerárquicos tradicionales, que ubican a la mujer en una posición de desventaja con relación al hombre, por ejemplo: las relaciones de 


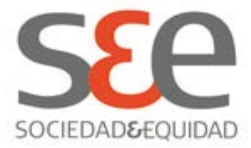

dominación/sumisión al interior del grupo doméstico, la división de lo público/privado, lo productivo/reproductivo, y la construcción de la identidad femenina en función de otros, asociada a la ética del cuidado y principalmente a la maternidad.

En el otro extremo se ubica lo urbano, la clase social media, y la generación de los y las jóvenes como más permeable a los nuevos contextos, con relaciones de género más flexibles y menos restringidas por estos binarismos jerárquicos tradicionales antes descritos, dando cuenta de procesos de transformación y cambio en torno a las relaciones de género.

“En Lima, yo creo que ya en la capital, hay una variación; los jóvenes (...), están adquiriendo una mezcla de costumbres, como que son más libres, tanto los jóvenes como también las mujeres, y van saliendo van rompiendo un poco más los esquemas tradicionales, esquemas machistas, mientras que se mantiene mucho más fuerte en las regiones, y mucho más ponte tú, en el campo" (Nidia, refugiada, lideresa organización social)

Las mujeres que formaron parte de esta investigación, se ubican en un punto medio entre uno y otro extremo, manifestando por un lado una cierta sujeción a la norma, reconociendo que fueron socializadas en contextos más bien tradicionales, donde se encontraba legitimada la sumisión de la mujer y "respeto" al hombre, a sus decisiones y a las normas establecidas por él, pero también dan cuenta de la manera en que dichas normativas vienen siendo cuestionadas, negociadas y transformadas, en parte por los cambios generacionales, así como producto de su experiencia migratoria.

Así, el discurso de las entrevistadas confluyen un conjunto de experiencias múltiples, complejas y contradictorias, definido por variables que se superponen como la clase, el estilo de vida, la edad, las experiencias de pareja, maternidad, ejercicio de sexualidad, experiencias participativas previas y actuales, entre muchos otros; esto coincide con los planteamientos de posturas posfeministas, en las cuales se plantea que el "sujeto mujer" no se considera una esencia monolítica definida de una vez y para siempre; estas versiones alternativas de la subjetividad se oponen a la universalización de cualquier tipo de experiencia, incluida la experiencia sometida de la mujer, renunciando al ideal de una única visión (feminista) correcta (García-Selgas, 1996 en Gómez, 2003:242).

Cada una de estas mujeres ha construido y construye, a través de su discurso sus propias historias, sus propios significados sobre sí misma como 


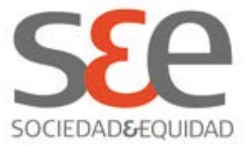

mujer, y una visión de las otras mujeres y sus historias. Si bien los anteriores puntos podrían englobarse dentro de una categoría general del "ser mujer", éstos se distancian, contraponen y complementan, y ejemplifican procesos de subjetivación abiertos, inacabados y múltiples, que en cierta medida desafían las identidades impuestas.

De otra parte, el análisis de los diversos posicionamientos de sujeto desde el cual las mujeres articulan su discurso, en ocasiones como inmigrantes, en otras como mujeres, y en otras como pertenecientes a un grupo u organización particular, también resaltan que la categoría genérica y generalizada del "ser mujer", contiene en su interior un sinnúmero de identidades, que se construyen a partir de la enunciación de Otro: "otras mujeres", "otro tipo de inmigrantes", "mujeres que pertenecen a otro tipo de organizaciones". Esta enunciación del Otro se da en el marco del establecimiento de relaciones distintas, en ocasiones de acuerdo, en otras de conflicto, al interior de ese grupo de "mujeres inmigrantes", catalogado como homogéneo en diversas investigaciones y por la sociedad en general.

Las identidades sociales, y así mismo las relaciones de género, se tejen a partir de una pluralidad de descripciones diferentes que surgen de prácticas de significaciones diferentes; por lo tanto, nadie es simplemente una mujer, puesto que todos actuamos en una pluralidad de contextos sociales; las diversas descripciones que comprende la identidad social de cualquier individuo entran y salen del centro de atención.

\section{Los cambios y continuidades en las relaciones de género que se construyen en el discurso de las mujeres entrevistadas}

Para analizar los cambios y continuidades en las relaciones de género, nos basamos en el concepto de "dominación masculina", desarrollado por Bourdieu $(2000)^{2}$, como una forma paradigmática de violencia simbólica, aquella violencia que se ejerce sobre un agente social con su complicidad o consentimiento. Afirma el autor que el orden masculino está tan profundamente arraigado que no requiere justificación, se impone a sí mismo como autoevidente, y es tomado como natural, gracias al acuerdo casi inmediato que obtiene, por un lado, de estructuras sociales, y por otro, de estructuras cognitivas inscritas en los cuerpos y en las mentes de las personas.

Tomando como referencia este marco teórico, podemos afirmar que gran parte del discurso de las mujeres se enfoca a reconocer situaciones de dominación, en las cuales ellas u otras mujeres cercanas estuvieron o continúan estando insertas al interior de sus relaciones en el grupo doméstico,

2 Se retoma el concepto de "Dominación Masculina", desde los planteamientos de Bourdieu (2000), mencionados en el apartado anterior. 


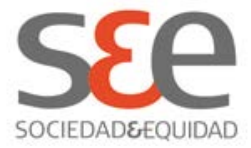

comunitario y en general a discursos sociales que circundan en sus contextos más cercanos.

Nosotras respetamos mucho a la pareja, como que la mujer tiene más internalizado que la mujer es más como propiedad del marido, a que la mujer tiene que servir al marido, a que la mujer tiene que cumplir bien su rol materno dentro de la casa, eso en Perú está como más atrasado, la mentalidad, se mantiene la idea (Susana, inmigrante laboral, participante organización social).

Como se expresa en los testimonios de las entrevistadas, y como lo señala igualmente Velázquez (2006), las relaciones de género, evidencian que varones y mujeres no tienen una posición igualitaria en la vida cotidiana, sino que esas relaciones son organizadas como formas variables de dominación. Ahora bien, la existencia generalizada de formas de socialización diferenciadas para las mujeres y los hombres, genera y sirve de fundamentación a las diferencias que se consideran importantes para unas y otros; hay aprendizajes encaminados a la aceptación de lo hegemónico (Del Valle, 2002):

(...) la generación mía, por ejemplo, todavía hemos crecido con los mandatos instalados en las mujeres de casi ser servil, de servidumbre, ¿no? de servir a los varones, de supeditarse un poco a las decisiones que toman los varones (Martha, refugiada, lideresa organización social).

Además de reconocerlos, las mujeres problematizan los binarismos jerárquicos que establecen distinciones entre lo permitido y no permitido para mujeres y hombres, y que reproducen relaciones asimétricas (dominación/sumisión) entre ambos géneros. Así por ejemplo, se cuestiona la existencia de una fuerte normativa de "respeto", "servicio" y sumisión frente al hombre, del confinamiento de la mujer al espacio doméstico y su avocamiento a las funciones de crianza, así como la forma en que se controla desde lo familiar y lo social la elección de pareja por parte de la mujer. Al respecto, dan cuenta de su oposición a dichas normativas, y plantean diversas prácticas que ellas y otras mujeres han puesto en marcha para salir de estos constreñimientos; entre ellos, uno de los más valorados es la posibilidad de insertarse en el campo productivo $y$, de esta manera, obtener independencia económica que les permite mayor autonomía en la toma de decisiones sobre ella misma y sobre cuestiones concernientes al hogar. Dicha posición se ve aún más reforzada con el proceso migratorio, ya que con frecuencia las mujeres se convierten en las principales proveedoras del hogar, lo cual otorga una posición de mayor poder en la toma de decisiones al interior del grupo doméstico, pero 


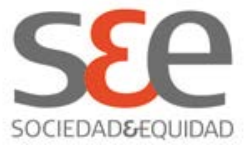

esto también va acompañado de una fuerte culpa por abandonar la función principal otorgada a la mujer frente a la crianza de sus hijos.

Otro de los aspectos problematizados guarda relación con el control social hacia la mujer frente a la elección de pareja y la conformación de familia, la cual debiera ser una decisión única y permanente. Lo anterior es cuestionado por las mujeres a partir de la migración, al establecer comparaciones con la mayor libertad con la que cuentan las mujeres en Chile para elegir pareja, establecer uniones de hecho, generar rupturas con sus relaciones conyugales anteriores cuando éstas no permiten negociación de ciertos aspectos, y no es posible el establecimiento de relaciones más simétricas.

O sea las mujeres que migran han logrado cambios, que es distinto a las que se han quedado allá, por ejemplo, que ellas se sienten de repente con mayor decisión, capacidad de decisión (...) una vez que ya emigran y salen de ese hogar, acá incluso son capaces hasta de volver a rehacer su compromiso con otra pareja, ¿no? (...) De estar allá no poh, no, no sería así, (...) o sea de repente la distancia ayuda un poco a que salgan de ciertas cosas ¿no? (Cecilia, refugiada, lideresa de organización social)

Respecto a los posicionamientos frente a las rupturas conyugales propiciadas por las mujeres dentro del contexto del proceso migratorio, estos oscilan entre dos visiones opuestas. Por una parte, la visión de esta decisión como un paso que evidencia mayor autonomía, y por el otro lado la visión que juzga y culpabiliza a la mujer por desintegrar el hogar, y que se basa en la legitimación de la mujer como sostén principal del hogar. Desde la propia experiencia, las mujeres narran la manera en que han logrado establecer relaciones más simétricas con sus actuales parejas, muchas de ellas conformadas después de la migración, en las que el diálogo y la negociación son factores centrales, que les han permitido re-significar los mandatos de dominación/ sumisión en los cuales fueron socializadas.

... tu idea cambia, porque tú te das cuenta que tu como mujer ivales tanto!, que tú no puedes dejar que te gritoneen que te insulten; yo le digo a él, yo necesito que tu cumplas tu rol, tú eres mi marido pero también puedes ser mi amigo, mi amante, y entonces lo importante que tenemos que tener los dos es comunicación, conversar harto, ah! y todo lo que yo aprendo igual lo transmito. (Susana, inmigrante laboral, participante en organización social). 


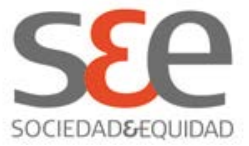

Lo anterior permite ver entonces que, si bien las mujeres se encuentran sujetadas a ciertas formas particulares de dominación, instaladas en diversos dispositivos de poder, su actuación al interior de dichos dispositivos y de las relaciones en las cuales están insertas no es siempre pasiva, y por tanto no implica una condena de repetición de las mismas; las mujeres ponen en evidencia su propia capacidad de agencia, y la de otras mujeres para crear y recrear nuevas prácticas sociales que interpelan los órdenes discursivos y los dispositivos institucionales que las han constituido.

Ahora bien, aunque existe una problematización de diferentes aspectos involucrados en las relaciones de género desde la visión de las mujeres, dos aspectos aparecen fuertemente naturalizados en su discurso: la maternidad como parte de su naturaleza femenina, y con relación a ésta, su identidad "en función de" o "para los otros". Si bien estos dos aspectos son problematizados por algunas de las lideresas, la mayoría de las mujeres continúan reforzando y reproduciendo el discurso hegemónico, de la maternidad y la mayor capacidad y vocación de las mujeres para el cuidado y la crianza.

El proceso migratorio ha permitido a las mujeres ver "otras maternidades" y, por tanto, comparar sus significados y prácticas asociadas al ser madre; por ejemplo, al realizar comparaciones, plantean que las mujeres chilenas son "más mujeres que madres", mientras que las mujeres peruanas son "más madres que mujeres". Con referencia a esto es importante acotar que aunque no hay un desprendimiento de la identidad femenina asociada a la maternidad, ésta se convierte en una esfera, muy importante pero no la única dentro del ser mujer, pues también consideran dentro de sus prioridades el desarrollo personal, el desarrollo laboral, y la vida en pareja.

... (en las chilenas) es como importante la tarea materna, ¿no cierto?, pero no tanto como las peruanas, de repente que nosotros nos enseñan que hay que ser aglutinados con los hijos, (...) entonces eso es distinto, la costumbre es distinta de las familias, el concepto de familia es distinto, porque nosotros estamos como un paso más atrás de Chile, yo creo que de aquí a diez años va a ser distinto allá en Perú ¿no cierto? (Susana, inmigrante laboral, participante en organización social)

La naturalización de la maternidad como parte de la identidad femenina, resulta asociada la idea de la "vocación" de la mujer para el cuidado y crianza de los hijos; por lo tanto, cualquier tipo de práctica que implique limitar los tiempos y espacios dedicados a la maternidad y la crianza, lleva implícita la culpa por no cumplir aquello que les ha sido legítimamente asignado. De esta manera, el alejamiento de estas prácticas conlleva una doble 


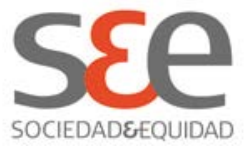

sanción, la externa o social por no cumplir con el ideal de "buena madre", así como la auto-sanción por parte de las mujeres. En este sentido, resulta relevante observar cómo las mismas mujeres, por una parte justifican la sobrecarga que ha traído su incursión en lo social, y que no ha ido acompañada de una redistribución de las funciones reproductivas al interior del hogar; por otra parte, cuando la sobrecarga es imposible de manejar, ellas se autoexcluyen de ciertas actividades (por ejemplo la inserción en lo productivo, o los espacios de participación), y por tanto auto-restringen sus posibilidades de mayor libertad, en función de responder a aquello para lo que sienten que fueron hechas. Lo anterior da cuenta, de la forma en que la violencia simbólica que caracteriza las relaciones de dominación, actúa con la "complicidad" de quien la sufre (Bourdieu, 2000:49).

Desde el análisis de las relaciones de género como relaciones de poder ${ }^{3}$, interesa analizar cómo aquellos elementos problematizados por las mujeres, guardan relación con esas mismas categorías impuestas y legitimadas culturalmente: "el ser pareja", "el ser madre" y las funciones de producción y reproducción, en las cuales ellas se reconocen como mujeres; al hablar de sí mismas o de las otras mujeres, los discursos se construyen a partir de esas identidades naturalizadas como parte del ser mujer, y por tanto, repiten y mantienen esas identidades impuestas antes que subvertirlas. De esta manera, se determina y legitima la visión dominante como natural, y evidencia cómo el poder no se manifiesta siempre como una norma que nos prohíbe sino que el entramado de poder/ saber penetra los cuerpos, las voces y las vidas.

El cuestionamiento que surge en este sentido, radica en que si la mujer dejase de hablar desde esas categorías socialmente legitimadas para el ser mujer y a través de las cuales se ha construido ¿Qué le queda? ¿Desde dónde podría entonces articular su propia identidad de mujer sin referencia a lo que ella es a diferencia del hombre?; Así pues, una mujer es mujer en la medida en que funciona como mujer en la estructura heterosexual dominante, y poner en tela de juicio la estructura posiblemente implique perder algo de nuestro sentido del lugar que ocupamos en el género (Butler, 2007:12).

\footnotetext{
${ }^{3}$ Amigot y Pujal (2009), plantean que existe controversia acerca de la pertinencia de la obra foucaultiana para la teorización y las prácticas feministas; Michel Foucault nunca examinó específicamente la subordinación de las mujeres o las fuentes de su subjetivación y según algunas autoras, en el proceso de elaboración de sus herramientas teóricas y analíticas olvida analizar cómo el género anida en y alimenta las estrategias desplegadas por los dispositivos de poder; no obstante, ellas plantean que su obra brinda herramientas imprescindibles para la comprensión de las relaciones de poder, de su reproducción y de su transformación.
} 


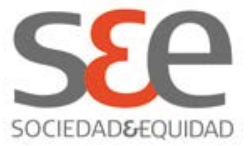

Por último, frente a los cambios y continuidades en las relaciones de género que aparecen en el discurso de las inmigrantes participantes en esta investigación, interesa rescatar aquellos elementos que oscilaron entre la agencia y la sujeción a la norma; aspectos que si bien fueron problematizados por las mujeres como nuevas prácticas que generan tensión frente a los discursos dominantes, aún son catalogados por ellas como cambios "negativos" y por tanto producen la legitimación de un deber ser femenino que prescribe ciertas prácticas como adecuadas e inadecuadas y por tanto conlleva una carga de sanción social y exclusión a quien no cumpla con dichas adecuaciones. Específicamente, las mujeres refieren a nuevas prácticas propiciadas por el contexto migratorio, en el que las mujeres que por lo general llegan solas (sin hijos, y sin pareja), se sienten con mayor libertad y menos constreñidas por los controles sociales existentes en su país:

(...) yo lo sentí, yo me acuerdo en algún momento en las primeras etapas, de sentirte que ya, como que te desprendes un poco del qué dirán, porque una sociedad tan machista, tan castigadora, con la mujer ¿no? (...) o sea yo vine acá y sentía esa sensación "aquí nadie me va a juzgar" (Nidia, refugiada, lideresa de organización social).

Esta sensación de mayor libertad y autonomía, se expresa por una parte, en el ámbito público, donde la mujer tiene nuevos comportamientos que no serían permitidos en su lugar de origen (asistir a espacios de "carrete" ${ }^{4} \sin$ pareja, tomar alcohol, fumar, permitir ser invitada por hombres a comer, bailar, entre otros) así como llegar a ejercer una sexualidad más abierta (tener varias parejas, establecimiento de relaciones temporales, negación de la pareja existente en Perú, mantener relaciones sexuales ocasionales).

(...) en ese bar era siempre lo mismo y no solamente peruanas, eran así entre todos (los inmigrantes), basta que te vean que tú eres mujer, como para decirte "ya, ehh sabes qué de aquí ya" todos terminan emparejados y no pue', la cosa era si tan fea decía yo, que la verdad que no, no", tu entrabas sola y salías emparejado, todo era súper... tan...tan...Sodoma y Gomorra por decirte, entonces todo lo veía así tan suelto, yo no sé si habrá cambiado eso". (Lina, inmigrante laboral, participante en organización cultural)

\footnotetext{
${ }^{4}$ El "carrete" en el contexto chileno, significa salir de fiesta, pasarlo bien.
} 


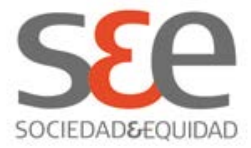

Desde lo performativo, las prácticas, actuaciones reiteradas que producen nuevas realidades, estos comportamientos podrían verse como actos subversivos que están generando tensión y fisura en la normatividad legitimada de la identidad femenina asociada al "ser casera", "pacata" o " respetarse a sí misma" (citas textuales de las mujeres), sin embargo, lo que se encuentra dentro del análisis discursivo, es que el relato de dichas fisuras va fuertemente cargado de una valoración negativa por parte de ellas, puesto que el "soltarse" se asocia con el "perderse" o "echarse a perder", lo cual pone de manifiesto dominaciones instauradas en lo discursivo, que legitiman lo socialmente esperado para la mujer -reservarse al ámbito privado- y que castigan socialmente cuando se intentan nuevas prácticas, limitando por tanto las posibilidades de acción de las mujeres.

(...) si vienen solas, se echan a perder, ¿sabes por qué? Porque la mujer viene sola, (...) comienza a formar un círculo de eso mismo, mujeres solas, que no tengan marido, no tengan hijos (en Chile), y hacen su círculo, (...) hacen ese tipo de vida (...) se olvidan de los hijos, se olvidan del marido que dejaron allá y luego de repente les gustó esta persona y se van alejando del otro, al final hacen otra vida acá con ese hombre, pero de los hijos no se olvidan están mandando plata, pero acá ya hacen otra vida con ese hombre, entonces digo iqué pena! (Mercedes, inmigrante laboral, participante organización social)

Ahora bien, no todas consideran estos comportamientos como negativos por sí mismos, ya que las lideresas reconocen en estas opciones nuevas posibilidades de actuación y libertad para las mujeres. Sin embargo, cuestionan dichas prácticas pues para ellas ponen de manifiesto una ausencia de auto-control por parte de la mujer, que no establece ciertos límites que la protejan de consecuencias negativas para sí misma (como embarazos no deseados, adquisición de enfermedades de transmisión sexual, entre otros).

(...) frente a esa situación como que es tan fuerte, ¿no? o sea, también castigan a la mujer o sea ¿no? ahí hay una vinculación de que nosotras las mujeres peruanas somos fáciles, o sea están buscando pareja, hay un lugar específico donde vamos allá y las encontramos... (¿Eso lo has oído en comentarios de chilenos o de los peruanos?) Si, de los chilenos, de los mismos taxistas peruanos y chilenos. (Nidia, refugiada, lideresa de organización social) 


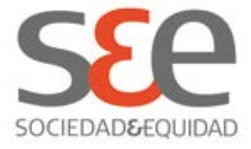

(...) yo creo que hay un asunto que no manejan todas las mujeres entonces caen en el otro extremo, (...) y entonces es súper complicado ahí poh, o sea a dónde, cómo te explicas tú, que llegan a un límite que ya no puedes controlar eso, tú misma. (Nidia, refugiada, lideresa de organización social)

Siguiendo nuevamente a Butler (2007), la acción del género exige una actuación reiterada, la cual radica en volver a efectuar y a experimentar una serie de significados ya determinados socialmente, y ésta es la forma ritualizada de su legitimación; desde esta perspectiva, estos espacios de "carrete" como espacios en los cuales las mujeres están poniendo en juego nuevas actuaciones que deslegitiman, 0 al menos en primera instancia desnaturalizan el ideal de lo que ha sido impuesto como comportamiento "adecuado" o "inadecuado" en ellas. Estas actuaciones podrían entonces ser vistas como deformidades que demuestran la identidad como una construcción constante, no sustancial y por tanto, posible de transformar.

\section{Sobre las articulaciones entre migración, relaciones de género y procesos participativos}

Buscando establecer articulaciones entre las relaciones de género y la participación de las mujeres inmigrantes en las organizaciones sociales y culturales, el discurso se articula desde dos posiciones de sujeto significativamente diferentes: las experiencias de las mujeres en condición de refugio político y las experiencias de las mujeres que migran por motivaciones laborales o económicas.

Al respecto, las mujeres que migraron por motivaciones de tipo económico o laboral, al llegar al nuevo contexto se abocan al ámbito productivo, restringiendo significativamente los espacios y posibilidades de participación, mientras que las inmigrantes en condición de refugio, procuran dar continuidad a su trabajo social, político y comunitario en Perú, articulando redes y liderando procesos de organización comunitaria que potencian la participación propia y de otras mujeres inmigrantes.

Yo vengo en otra en situación, porque de una y otra forma el estatus de refugiado te protege un poco más ¿no? (...) por ejemplo (...) la cédula de identidad (...) a mi me la dieron en menos de medio año, y en el caso de las mujeres que vienen en términos de laboral vienen sin contrato, 


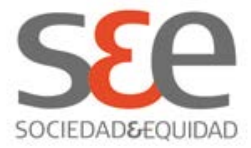

entran con visa de turista, (...) tienen que buscar un contrato de trabajo para que ellos recién puedan hacer el trámite este de la cédula y muchas veces no les resulta (...), (las refugiadas) hemos tenido más oportunidades laborales, (...) hemos podido conseguir alguna beca que nos ha permitido tener una sobrecalificación tal vez para competir, poder insertarnos en algunos puestos de trabaj o... ehh cosa que no pasa con las mujeres migrantes de este flujo de migración más vinculado a las razones laborales". (Martha, refugiada, lideresa de organización social)

Las redes sociales ${ }^{5}$ como facilitadoras de la vinculación a los espacios de participación, se configuran como centrales para ambos grupos de mujeres, pero con marcadas diferencias; las inmigrantes en calidad de refugio se refieren a la articulación de redes institucionales y organizativas que facilitaron su integración, así como su vinculación laboral en el nuevo contexto; para las inmigrantes laborales, el énfasis está puesto en las redes de tipo horizontal constituidas por familiares, amigos y vecinos que acompañaron y potenciaron tanto el proceso migratorio como la posterior inserción en la ciudad y en el ámbito productivo.

Dese la perspectiva de la teoría de la articulación expuesta en el apartado teórico, puede afirmarse que las redes constituidas por las inmigrantes refugiadas fueron más abiertas, dispersas y heterogéneas y por tanto abrieron mayores campos de movilización. Sus discursos hacen marcado énfasis en que su condición facilitó el acceso a la ciudadanía (obtención de la cédula, oportunidades de educación, entre otras), e igualmente brindó oportunidades para realizar trabajos voluntarios y vinculación con otras organizaciones de inmigrantes refugiados, que les permitieron dar continuidad al trabajo social y político que ya venían realizando en su país. De esta manera, su papel como actuales lideresas de las organizaciones responde, por una parte, a una agencia personal que las llevó a buscar los espacios de

\footnotetext{
${ }^{5}$ Las redes sociales se configuran como un conjunto de relaciones complejas en un espacio social dado, y tomando en cuenta que "cada individuo cuenta con un stock de relaciones reales o potenciales, heredadas 0 adquiridas y cada persona es el centro de una red de solidaridad y, a la vez, es parte de otras redes" (Lomnitz, 1994 en Pedone, 2004:108); en esta red se genera un sistema de intercambio de bienes, servicios e información que para el caso de las entrevistadas, es un intercambio horizontal, de amistad, vecindad o parentesco, en el que el canje se da entre iguales a través de un sistema de reciprocidad.
} 


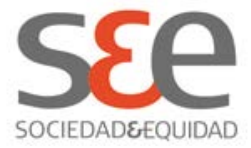

participación, como a la articulación de diferentes redes que les abrieron estas posibilidades.

Las redes de las inmigrantes laborales en el contexto de llegada fueron en cambio más homogéneas y densas (pocas vinculaciones, muy estrechas, con familiares y amigos) y por tanto con una movilidad más restringida. Por otra parte, estas mujeres no visualizan la participación como una de sus prioridades; el factor productivo cobra aquí especial relevancia pues su inserción en el ámbito laboral da cuenta de una estratificación social basada en el género, la nacionalidad y la clase, que las lleva a insertarse mayoritariamente en rubros inscritos en la cadena de cuidados, donde la vulnerabilidad y precariedad laboral son mayores, y las posibilidades de participación y vinculación a otros espacios son mucho más reducidas.

... es de que la mayoría de las mujeres acá trabaja incesantemente para mandar sus ahorros como remesa al país, porque se convierten, prácticamente en el elemento que sostiene a la familia; muchas de ellas o sea, dejan hijos, a veces no está el marido, no está el esposo como para que responda económicamente, son ellas las que se convierten en padre y madre, y se dedican a trabajar, o sea en una explotación, o sea la más terrible. (cecilia, refugiada, lideresa de organización social)

Lo anterior se suma además a la lógica individualista promovida por el contexto económico, que lleva a no visualizar la organización social o comunitaria como una opción para lograr mayor movilidad social, y que desintegra las redes comunitarias, más aún en el caso de las inmigrantes.

Esto se relaciona también con las significaciones otorgadas por las mujeres a los espacios participativos. Las migrantes refugiadas conciben y promueven la participación al interior de las organizaciones como espacios para articular movimientos sociales, para "difundir" ya sea los derechos o el folclor, pero en todo caso para visibilizar la población inmigrante y, además, lograr un impacto social tanto en la población chilena, como en el Estado y en la misma comunidad de inmigrantes.

Por su parte las inmigrantes laborales, quienes participan en las organizaciones en calidad de asistentes o como apoyo a la gestión de las lideresas, perciben este espacio como un espacio "familiar", que les permite articular las redes que se deterioraron a partir de la migración y la lógica individualista del mercado laboral en el cual están insertas; la participación se convierte entonces en una forma de establecer lazos de confianza, basados en 


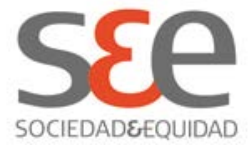

el apoyo y solidaridad mutua con otras mujeres inmigrantes en igualdad de condiciones. Por otra lado, también son percibidas como redes instrumentales a partir de las cuales circula información importante, ya sea en lo referente a estrategias para lograr el cumplimiento de derechos (principalmente en educación, salud y laborales), o información referente a oportunidades laborales o mecanismos de acceso a éstas.

Tanto las lideresas como las participantes han visualizado su proceso de vinculación a las organizaciones, como la posibilidad de tener "un espacio propio" para las mujeres, en donde puedan desarrollar o fortalecer aprendizajes, desligarse de su rol en función de otros, re-significar sus relaciones de género a partir del intercambio de experiencias similares (por ejemplo experiencias de violencia intrafamiliar, rupturas, conflictos familiares y laborales), que si bien en ocasiones no son el objetivo primordial del espacio de participación, se producen de manera espontánea.

El discurso de las mujeres entrevistadas, se mueve entre las limitantes externas y la capacidad de agencia de la propia mujer para mantenerse en el espacio participativo; como describimos anteriormente, ciertas condiciones macro-sociales (estratificación social de las inmigrantes con base en la nacionalidad, la clase y el género) han llevado a gran parte de las mujeres a insertarse en el trabajo "puertas adentro" como asesoras de hogar, independientemente de su cualificación técnica o profesional. Éste se ha constituido en un nicho laboral específico para las inmigrantes, que se caracteriza por la segregación y una mayor vulnerabilidad y precariedad en las condiciones laborales, que limitan significativamente los tiempos y espacios que las mujeres pueden dedicar a otros espacios propios.

Sumado a lo anterior, otra de las limitantes para la participación que se enuncia en el discurso de las mujeres, tiene relación con la dificultad para la articulación de las diversas funciones asignadas al género femenino: el cuidado y atención de los otros (hijos, pareja) en el escaso tiempo y espacio que la mujer tiene fuera de su rol productivo.

... en el caso de la mujer no valoran desde el principio, o sea no lo ven, no lo identifican, que de todas las múltiples tareas que hacen o los roles que cumplen las mujeres no lo ven como importante de darse un espacio para ellas, siempre está primero el marido, los hijos, la casa, siempre hay algo primero y la mujer siempre está al último, después. (Nidia, refugiada, lideresa organización social) 


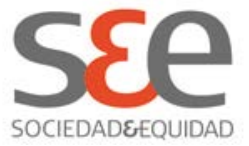

Existe una legitimación de que este espacio propio debe ser concebido para la mujer como un espacio familiar; por tanto, cualquier actividad alterna que le implique la desatención de este ámbito es cuestionado por los otros cercanos (pareja, hijos mayores) y vivido por ellas con culpa, lo que las Ileva a la propia auto-exclusión en virtud del cumplimiento de sus principales funciones asignadas y legitimadas socialmente. Sin embargo, las entrevistadas ubican estas limitaciones en aquellas mujeres que no participan, o que participaron alguna vez y abandonaron el colectivo, por la dificultad para articular el rol materno, conyugal y productivo con los espacios de participación.

¡¡Uyyy lo mío fue terrible!! Lo mío era como un tema de condiciones, mi pareja me decía "tú puedes (ir)" pero yo no voy, y no me obligues; trató de sacarme de ahí pero no pudo, me ponía entre la espada y la pared, "o tu grupo o yo" (...) me decía "escoge, o tu grupo o yo". (Myriam, inmigrante laboral, participante en organización cultural)

Las entrevistadas que se posicionan desde ese "nosotras, las que participamos", dan cuenta de diferentes estrategias que resaltan su movilización y agencia para hacer frente a estas restricciones normativas en las que se encuentra el común de las mujeres. Como estrategias utilizadas para mantener su participación en las organizaciones, mencionan prácticas de negociación, confrontación directa con la pareja, e incluso el ocultamiento, así como la inserción en otros contextos laborales, que aunque puedan igual pertenecer a un bajo escalón en la estratificación social, les ha permitido mayor movilidad y ha facilitado su participación.

Con respecto a la maternidad, como otra de las principales esferas desde las cuales las mujeres participantes articulan su identidad femenina y que limitan su participación, se mencionan diversas estrategias utilizadas por ellas para articular ambas actividades, dentro de las cuales destacan la utilización de redes de familiares y amigas para el cuidado de los menores, así como la inclusión de los niños en los espacios de participación cuando ésta es posible.

\section{Algunas acotaciones finales}

Del análisis anterior es posible concluir que el discurso de las mujeres participantes se mueve en un proceso inacabado y constante de refutamiento de las normas socialmente legitimadas, pero a la vez hacerse parte de ellas; entre la posibilidad de subversión a través de sus actos, y el volver a la norma cuando se experimentan las consecuencias punitivas. Así, la construcción de su identidad a partir de su discurso es un ir y venir entre el deber ser, los discursos socialmente legitimados y por otro lado su capacidad de acción y la 


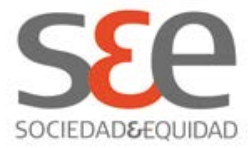

posibilidad de construirse como agentes en su discurso y a través de él, rescatando la posibilidad de cambiar esa repetición.

Esto da cuenta de cómo somos a la vez sujetos y sujetados, y lleva a un reconocimiento de nuestra imposibilidad para actuar fuera de las relaciones de poder, pero aceptando que dichas relaciones pueden ser cuestionadas, resignificadas y transformadas; asumiendo igualmente, que la desigualdad y dominación de género no puede ser generalizada a una situación global y homogénea de todas las mujeres, sino reconociendo que existen "gradaciones" de poder al interior de las relaciones, que pueden ir de la pura dominación a una mayor capacidad de agencia.

Uno de los principales retos que enfrentan las organizaciones es la dificultad en la convocatoria para la participación, y el mantenimiento de las mujeres en dichos espacios; el análisis aquí realizado permite identificar elementos relevantes que pueden explicar esta dificultad, y sobre las cuales es posible articular estrategias que permitan lograr un mayor impacto de las organizaciones en la población inmigrante general. Uno de los elementos significativos que se destacan de esta investigación, es la agencia de las mujeres, tanto lideresas como participantes, para promover y potenciar la participación de ellas mismas y otras inmigrantes a través de sus organizaciones, buscando con ello un impacto en lo social -sociedad chilena, Estado- pero además persiguiendo un bienestar personal y comunitario.

Desde una perspectiva situada de la intervención social (Montenegro, 2001), es importante reconocer esta agencia de las mujeres inmigrantes para su organización y acción social, así como su "experticia" en el trabajo en terreno, la cercanía y conocimiento a profundidad de la población inmigrante, sus condiciones de vida, problemáticas y fortalezas. Desde esta mirada, el presente análisis arroja insumos importantes que podrían facilitar un proceso de Investigación-Acción participativa, tanto con los líderes y lideresas de las organizaciones, así como con las mismas participantes -y también con quienes no participan- para definir aquello que ellos consideran problemático; a partir de allí se abre la posibilidad de desarrollar planes de acción desde su propia mirada y con el compromiso de todos los implicados, de manera que tanto el impacto personal que las mujeres perciben por su participación, así como el impacto social que las lideresas esperan de sus organizaciones, puedan ser articulados.

Por último, se reitera que el presente análisis propició un acercamiento a aquello naturalizado y/ o problematizado en el lenguaje; como plantean Magaña y Pallavicini (2007:279), no se trata del desconocimiento de factores macrosociales que limitan la movilidad y transformación social, sino del reconocimiento de que dichas limitantes se construyen y reconstruyen a partir 


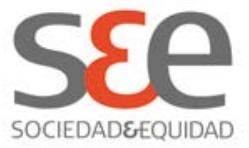

del lenguaje, las prácticas y las relaciones sociales; se pretende asumir el poder como existente en todas las relaciones y reconocer la posibilidad de resistencia y acción; estos principios conllevan el reconocimiento del potencial de cambio inscrito en el sujeto, como también de la necesidad de cambio en el plano de lo simbólico, que es donde podría situarse uno de los objetos de intervención.

\section{Referencias bibliográficas}

Arellano, M. (2004). La inserción social de las inmigrantes latinoamericanas en España: Migraciones laborales y género. Tesis doctoral Facultad de Ciencias Políticas y Sociología, departamento de Ciencia Política. Universidad Complutense de Madrid. España.

Amigot, P. y Pujal, M. (2009). Una lectura del género como dispositivo de poder. Sociológica, 24(70), 115-152.

Bourdieu, P. (2000). La dominación masculina. Madrid: Anagrama.

Butler, J. (2001). El género en disputa: el feminismo y la subversión de la identidad. México: Paidós.

Butler, J. (2004). Regulaciones de género. La ventana, 23.

Del Valle, T. (2002). Modelos emergentes en los sistemas y las relaciones de género. España: Narcea.

Foucault, M. (1992). Curso del 14 de enero de 1976 y Poderes y estrategias. En Microfísica del poder. España: La Piqueta, 139-152.

Gómez, L. (2003). Procesos de Subjetivación y Movimiento Feminista. Una Aproximación Política al Análisis Psicosocial de la Identidad Contemporánea. Universitat de Valencia

Gregorio, C. (2004). Entre la inclusión y la exclusión de la ciudadanía: procreadoras, madres y personas. Asparkía. Investigación Feminista, 15, 11-26.

Gregorio, C. (2009). Mujeres inmigrantes: Colonizando sus cuerpos mediante fronteras procreativas, étnico-culturales, sexuales y reproductivas. Revista Viento Sur. 104, 42-54.

Iñiguez, L. (2003). Análisis de discurso. Barcelona: Editorial UOC.

Lipszyc, C. (2004). Feminización de las Migraciones: Sueños y realidades de las mujeres migrantes en cuatro países de América Latina., En Caminar sin miedos. Montevideo, 13, 14 y 15 de abril de 2004. 


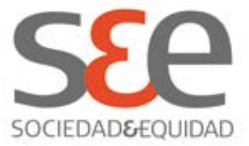

Magaña, I. y Pallavicini, P. (2007). La psicología comunitaria y el sujeto contemporáneo: Una posición crítica. En Psicología comunitaria en Chile: Evolución, perspectivas y proyecciones. Santiago, Chile: Ril Editores.

Montenegro, M. (2001). Conocimientos, Agentes y Articulaciones: una mirada situada a la intervención social. Tesis Doctoral, Programa de Doctorat en Psicología Social. Universitat Autónoma de Barcelona. España

Pedone, C. (2004). "Tú siempre jalas a los tuyos". Las cadenas y las redes migratorias de las familias ecuatorianas hacia España. Tesis doctoral Departamento de geografía, Facultad de Ciencias Sociales. Universidad Autónoma de Barcelona. España.

Stefoni, C. (2001). Representaciones Culturales y Estereotipos de Ia Migración Peruana en Chile. Informe final del concurso: Culturas e identidades en América Latina y el Caribe. Programa Regional de Becas CLACSO. 2001.

Stefoni, C. (2004). Inmigrantes transnacionales: la formación de comunidades y la transformación en ciudadanos. Capitulo 9. FLACSO, sede Chile. URL: http:/ / bibliotecavirtual. clacso. org. ar/ ar/ libros/ chile/ flacso/ artstef. pdf consultado el 10/07/2009

Stefoni, C. (2005). Comunidades transnacionales y la emergencia de nuevas oportunidades económicas: de empleados a empresarios. Persona y sociedad. Vol. XIX No. 3. Pp. 183-197. Universidad Alberto Hurtado. Chile.

Tijoux, M. (2002). Morderse la lengua y salir adelante. Amérique Latine Histoire et Mémoire. Les Cahiers ALHIM, 5 | 2002, [En línea], Puesto en línea el 23 juin 2006. URL: http://alhim.revues.org/index639.html. consultado el $10 / 03 / 2010$

Tijoux, M (2007). Peruanas inmigrantes en Santiago: Un arte cotidiano de la lucha por la vida. Polis, 18.

UNFPA (2006). Estado de la población mundial 2006. Hacia la esperanza: Las mujeres y la migración internacional. Fondo de Población de las Naciones Unidas

Velázquez (2003). Violencias cotidianas, violencia de género. Escuchar, comprender, ayudar. México: Paidós.

Zavala, X. y Rojas, C. (2005). Globalización, procesos migratorios y Estado en Chile. En Migraciones, Globalización y Género en Argentina y Chile. Programa Mujeres y Movimientos Sociales en el marco de los procesos de integración regional en América Latina, apoyado por la Fundación Heirinch Böll. Argentina. 